\title{
Vulnerabilidade socioambiental, inundações e repercussões na Saúde em regiões periféricas: o caso de Alagoas, Brasil
}

\author{
Social and environmental vulnerability, flooding \\ and repercussions on public health in underdeveloped regions: \\ the case of the state of Alagoas, Brazil
}

Neison Cabral Ferreira Freire ${ }^{1}$

Cristine Vieira do Bonfim ${ }^{1}$

Claudia Eleonor Natenzon ${ }^{2}$

${ }^{1}$ Diretoria de Pesquisas Sociais, Fundação Joaquim Nabuco. Av. Dezessete de Agosto 2187, Casa Forte. 52.061-540 Recife PE Brasil. freire.neison@gmail. com

${ }^{2}$ Programa de

Investigaciones en Recursos Naturales y Ambiente, Facultad de Filosofía y Letras, Universidad de Buenos Aires.

\begin{abstract}
The scope of this article is to analyze the social and environmental vulnerability of the population affected by disasters adopting the floods that occurred in the State of Alagoas in 2010 as a case study. For this, research was conducted in the Scielo and Medline databases as well as books, dissertations and theses. In addition, newspaper articles published in the local and national press about these floods were located and examined. A visit was made to some of the individuals who were affected by the flood and subsequently housed in the Santa Fé Prison Colony located in the municipality of União dos Palmares in the State of Alagoas. Among other aspects, the vulnerability is a consequence of the precarious living conditions of this population. However, even among the vulnerable there are some groups that are even more vulnerable without any possibility of changing a situation of chronic repetition of the disaster, perpetuating the vicious cycle of poverty and precarious living conditions.
\end{abstract}

Key words Social vulnerability, Floods, Disasters, Public health.
Resumo Este artigo tem por objetivo analisar a vulnerabilidade socioambiental das populações afetadas por desastres, adotando como estudo de caso as inundações ocorridas no Estado de Alagoas, Brasil, em 2010. Para tanto, foram pesquisadas as bases de dados Scielo e Medline, livros, dissertações e teses. Além disso, foram levantadas e analisadas matérias publicadas na imprensa local e nacional sobre essas inundações. Realizou-se também uma visita à Colônia Prisional Santa Fé, localizada no município de União dos Palmares $(A L)$, onde se encontra abrigada parte da população afetada por inundações. A vulnerabilidade resulta, entre outras coisas, de condições de vida precárias dessa população. Mas, mesmo entre os vulneráveis há alguns grupos que se tornam ainda mais vulneráveis, vivenciando sem possibilidades de mudança uma situação de cronificação do desastre, de perpetuação do ciclo vicioso da pobreza e das precárias condições de vida.

Palavras-chave Vulnerabilidade social, Inundações, Desastres, Saúde pública 


\section{Introdução}

O crescimento da população global, a pobreza, a escassez de terra e a urbanização em muitos países têm aumentado o número de pessoas que vivem em áreas propensas a desastres. Em associação às mudanças climáticas, tais fatos têm provocado o aumento da ocorrência de desastres desencadeados e intensificados por eventos extremos. Nos últimos anos, as inundações aumentaram em frequência e intensidade nos centros urbanos seja em função das condições naturais ou das atividades humanas pelo desmatamento, degradação do solo, urbanização e drenagem urbana ineficiente ${ }^{1-3}$.

Os desastres resultam de um evento adverso natural ou provocado pela ação humana, sobre um ecossistema vulnerável, causando danos humanos, materiais e ambientais e consequentes prejuízos econômicos e sociais ${ }^{4}$. Por conseguinte, o desastre envolve os perigos naturais e a vulnerabilidade. Entre os desastres, as inundações destacam-se como as mais comuns ${ }^{5,6}$. Estima-se que mais de 226 milhões de pessoas são afetadas pelos desastres a cada ano, das quais 102 milhões $(45,1 \%)$ são afetadas pelas inundações 7 . As inundações constituem a principal causa de óbitos por desastres no mundo e foram responsáveis por 6,8 milhões de mortes no Século XX. Para o período compreendido entre 1980 e 2009, foi estimado um total de 539.811 óbitos e 361.974 feridos, embora se considere que esses dados estejam subestimados ${ }^{8}$.

No Brasil, observa-se situação semelhante à tendência global com aumento da gravidade e frequência das enchentes, em consequência das condições de vulnerabilidade socioambiental, combinando-se com os aspectos sociais, ambientais, políticos, econômicos e culturais9. A ocupação de áreas de risco associada às condições socioeconômicas, potencializa as consequências dos desastres e os impactos nos grupos sociais ${ }^{10}$. De acordo com o Atlas Brasileiro de Desastres Naturais, entre as décadas de 1990 e 2000, houve a ocorrência de 6.671 desastres causados por inundações brusca e alagamentos no país ${ }^{11}$. No Estado de Alagoas, as inundações não são um fato novo. Nos últimos cem anos, sete grandes inundações (1914; 1941; $1969 ; 1988 ; 1989 ; 2000 ; 2010)$ atingiram as bacias dos rios Paraíba e Mundaú ${ }^{12}$. A Figura 1 apresenta um quadro evolutivo das principais inundações em Alagoas, demonstrando aumento no número de desabrigados e óbitos.
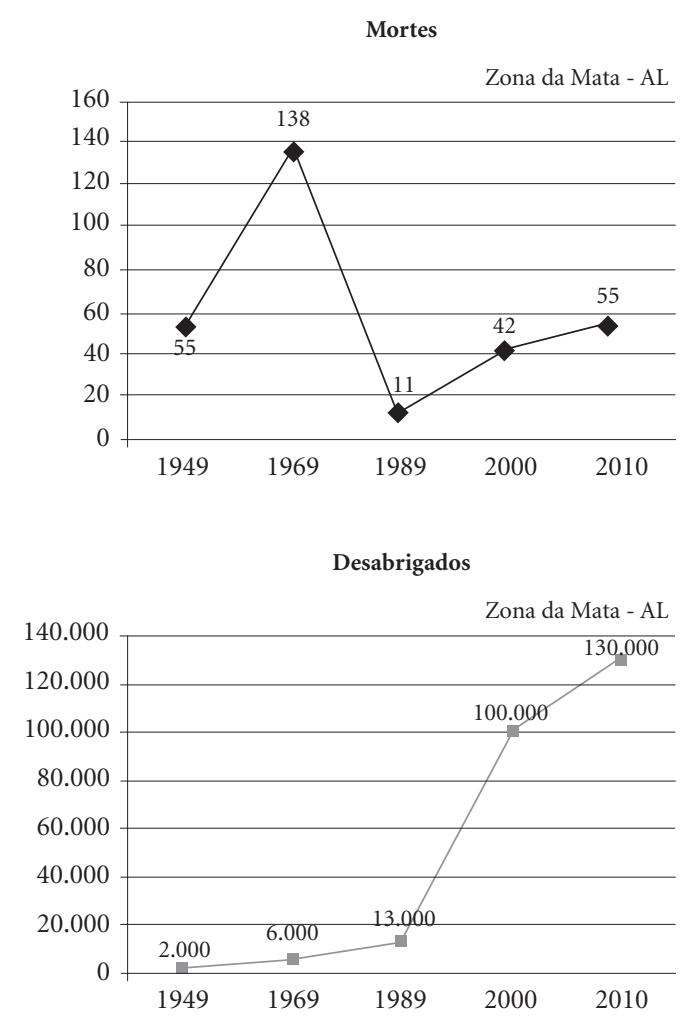

Figura 1. Mortes e desabrigados nas principais inundações em Alagoas nas últimas décadas.

Fonte: Defesa Civil de Alagoas (2012).

No que diz respeito aos impactos humanos, as inundações combinam condições ambientais (topografia, cobertura vegetal e clima, por exemplo) e socioeconômicas (densidade populacional e situação das moradias, emprego e renda, acesso à educação e serviços de saúde, por exemplo) $)^{6}$. Nesse processo, os grupos populacionais e os espaços geográficos mais vulneráveis são os mais fortemente afetados ${ }^{13}$. Em geral, populações que vivem em aglomerados subnormais, ocupam terras consideradas inadequadas para uso residencial ou comercial, localizados em áreas mais baixas propensas a inundações e/ou encostas sujeitas a deslizamentos de terra, expondo as pessoas aos riscos de que as inundações transformem-se em desastres ${ }^{14}$.

Considerando que os desastres combinam processos naturais (como uma chuva forte ou a elevação do nível de um rio) com socioeco- 
nômicos, este artigo tem por objetivo analisar a vulnerabilidade socioambiental das populações afetadas por desastres, adotando como estudo de caso as inundações ocorridas no Estado de Alagoas, Brasil, em 2010. Para tanto, procedeu-se a pesquisas na literatura científica sobre o tema nas bases de dados Scielo e Medline, livros, dissertações e teses. Além disso, foram levantadas e analisadas as matérias publicadas na imprensa local e nacional sobre essas inundações. Por fim, realizou-se também uma visita à Colônia Prisional Santa Fé, localizada no município de União dos Palmares (AL), onde se encontra abrigada parte da população afetada pelas inundações.

\section{Risco e vulnerabilidade}

Este estudo concentra-se na abordagem da Teoria Social do Risco. Ulrich Beck ${ }^{15}$, considerado como um dos autores de referência da Teoria Social do Risco, chamou a atenção para vivermos em uma "sociedade de risco". Para o autor, vivemos em uma sociedade em que os danos são cada vez maiores, afetando uma boa parte da população do planeta. Embora os riscos tornem-se globais, isso não implica que todos sofram igualmente os danos.

No caso dos desastres, por exemplo, embora se constituam em um problema global, quando ocorrem em determinada localidade, acabam por afetar de modo mais severo alguns grupos populacionais mais do que outros, em função das desigualdades sociais existentes. Assim, deve-se avançar para a compreensão de que o risco não se realiza sem considerar as condições de vulnerabilidade, o que pode ser expresso através da seguinte equação: Risco $=$ Perigo $\mathrm{x}$ Vulnerabilidade ${ }^{15}$. $\mathrm{O}$ risco não se refere aos fenômenos naturais per si, mas a junção desses com os sistemas humanos e suas vulnerabilidades ${ }^{16-18}$.

A adoção da Teoria Social do Risco para o estudo dos desastres, e aqui especificamente das inundações, envolve quatro dimensões intimamente relacionadas entre si. À primeira refere-se a periculosidade, isto é ao potencial perigoso que tem os fenômenos naturais (espontâneos ou tecnicamente manipulados); A segunda dimensão é a vulnerabilidade que se define pelas condições socioeconômicas anteriores a ocorrência do desastre e pela capacidade de enfrentá-lo. Os níveis de organização e institucionalização e os planos de mitigação (preparação, prevenção e recuperação) também são componentes da vulnerabilidade; A terceira dimensão é a exposição que é uma consequência da interrelação entre periculosida- de e vulnerabilidade. Essa dimensão se expressa territorialmente como uma construção histórica que envolve processo físicos e naturais com as relações econômicas, contemplando o uso do solo, a infraestrutura, os serviços públicos, entre outros; A última dimensão é a incerteza que se relaciona com as limitações do conhecimento (limitações técnicas e as indeterminações quanto às competências e aos aspectos normativos - incerteza social). Ao mesmo tempo, essas limitações e a complexidade dos fenômenos das inundações dificultam o manejo adequado da totalidade das variáveis envolvidas e o processo de tomada de decisões é limitado e impregnado de incertezas ${ }^{19}$.

As características de vulnerabilidade de uma determinada população estão associadas às relações macro e microssociais que podem ampliar ou reduzir as suas defesas contra os perigos de natureza variada. Essas relações incluem a lógica organizadora do território, o acesso aos recursos naturais, aos bens materiais, aos serviços de infraestrutura e outros serviços públicos ${ }^{17,20,21}$. Especificamente no caso brasileiro, a pobreza estrutural associada à injustiça social contribuem para elevar a vulnerabilidade aos eventos hidromeoterológicos ${ }^{22}$. Dessa forma, compreende-se que a aplicação do conceito de vulnerabilidade é basilar para a identificação da população sob maior risco e, sobretudo, para a adoção de medidas de adaptação ou proteção da população ${ }^{23}$.

\section{A Construção Social da Vulnerabilidade}

Abordam-se os conceitos de risco e vulnerabilidade como importantes para a compreensão das particularidades dos fatos ocorridos, em 2010, na área de pesquisa, a bacia do rio Mundaú, que está parcialmente localizada numa das regiões menos desenvolvidas do Brasil: o Estado de Alagoas.

O Estado Alagoas, localizado na Região Nordeste do Brasil, faz parte de um contexto regional de profundas desigualdades sociais. O seu espaço agrário - locus da sua atividade produtiva desde os primórdios da colonização do Brasil - sempre foi cenário da monocultura da cana-de-açúcar. O meio ambiente sofreu as consequências dessa vasta ocupação: desde muito cedo, a Mata Atlântica foi totalmente desmatada para servir ao regime de plantação nessas áreas férteis de massapê (um tipo de solo argiloso). Restaram uns poucos espaços em ladeiras e fundos de vales, haja vista não serem adequados para o cultivo da cana-de-açúcar. Na realidade, essa "proteção ambiental" aconteceu devido à necessidade de assegurar fontes de água 
limpa a baixo custo, necessária para o processo industrial da produção de açúcar nos engenhos e nas usinas açucareiras, e, a partir da década de 1970, também do álcool das destilarias regionais/locais.

Dessa forma, a estrutura fundiária no Nordeste brasileiro foi, desde muito cedo, marcada pelo grande latifúndio, com poucos e poderosos proprietários, alta concentração de renda e grande vulnerabilidade social. Essa vulnerabilidade social tem a sua origem na matriz econômica historicamente construída.

À população socialmente vulnerável restou a ocupação de áreas inadequadas para residência, quase sempre muito perto das margens dos rios, cuja vegetação foi gradativamente eliminada para dar lugar à expansão da cana-de-açúcar, particularmente na década de 1980, quando se começou a utilizar novos fertilizantes químicos e técnicas industriais de produção em larga escala.

Essas inovações tecnológicas na plantation aumentaram o conteúdo de sacarose na canade-açúcar e, dessa maneira, as usinas conseguiram obter maior rentabilidade nos seus produtos finais. Isso permitiu esgotar as terras de cultivo da cana-de-açúcar em Alagoas. Associadas ao uso cada vez mais intensivo da mecanização, as mudanças também causaram uma diminuição no mercado de trabalho rural na Zona da Mata do Estado.

A migração que vinha do campo para as suas periferias, originou uma forte pressão em busca de serviços e infraestruturas urbanas, praticamente impossíveis de obter do poder público local.

Com tal configuração histórico-social, um evento climático extremo, ocorrido no mês de junho de 2010, provocou um desastre de graves repercussões socioambientais, principalmente na bacia do rio Mundaú, entre Alagoas e Pernambuco.

De fato, foi devido a múltiplas causas que o desastre se instalou: pelas precárias condições de manutenção dos diques nas bacias dos rios Mundaú e Paraíba e o desmatamento da vegetação nativa de suas margens, especialmente para a monocultura da cana-de-açúcar. Disso resultou a perda da capacidade de retenção de água, a erosão do solo e a sedimentação do leito dos rios.

Outro grave problema é a falta de um adequado planejamento urbano nas cidades, especialmente com a ocupação irregular ao longo das margens dos rios durante episódios periódicos de chuvas intensas. Esses fatores, juntamente com as chuvas extremas relacionadas às mudanças no sistema climático global, significam que a probabilidade de novos desastres na área é muito maior agora do que antes. Portanto, continuam existin- do as armadilhas espaciais para os habitantes dessas cidades.

\section{A inundação em Alagoas, 2010}

Entre os dias 18 e 20 de junho de 2010, um evento climático extremo, ocorrido, provocou um desastre com graves repercussões socioambientais, principalmente na bacia do rio Mundaú, entre Alagoas e Pernambuco, embora uma área maior também tenha sido atingida pelo desastre. Imagens de satélite e dados meteorológicos indicaram mudanças nos processos climáticos da Zona de Convergência Intertropical do Atlântico Norte. O fenômeno denominado Onda de Leste, caracterizado por uma conjunção de ventos fortes do oceano em direção ao interior do estado, por uma grande concentração de nuvens nas cabeceiras dos rios e por um aquecimento acima do esperado da massa do Oceano Atlântico ${ }^{24}$.

Devido a ininterrupta chuva que caía nas cabeceiras, os rios Mundaú e Paraíba, localizados entre os estados de Pernambuco e Alagoas, tiveram os seus níveis históricos de vazão superados, ocasionando a rápida elevação de lâmina d'água, o extravasamento do seu leito e a inundação de vários municípios ${ }^{25}$.

O desastre acarretou prejuízos ao ecossistema local e perdas e danos humanos irreparáveis. Em três dias de fortes chuvas, 26 municípios de Alagoas foram declarados em estado de calamidade pública, e 34 em estado de emergência. Os municípios de Murici, Rio Largo, Branquinha, União dos Palmares e Santana do Mundaú foram seriamente afetados pela inundação na bacia do rio Mundaú e os municípios de Quebrangulo e Paulo Jacinto pela inundação na bacia do rio Paraíba ${ }^{24,25}$, conforme observado na Figura 2.

Aproximadamente 1.5 milhão de pessoas vivia nos municípios afetados pelas chuvas, representando cerca de $50 \%$ da população residente no Estado de Alagoas. De acordo com o Relatório de Avaliação de Perdas e Danos aproximadamente 270 mil pessoas foram afetadas, das quais 44 mil ficaram desalojadas e 28 mil desabrigadas ${ }^{24}$ (Tabela 1).

O evento resultou em amplos e intensos impactos, disparando diversas medidas emergências, envolvendo ações do Corpo de Bombeiros, Defesa Civil, Exército, Força nacional, Força Armadas, Polícia Militar, várias secretarias estaduais, com destaque para a Secretaria de Saúde do Estado de Alagoas. Também houve uma forte mobilização da sociedade e dos meios de comunicação para arrecadação de donativos. 
Diversos prédios públicos foram destruídos, $150 \mathrm{~km}$ de ferrovias, três pontes ferroviárias, milhares de residências, entre outros. O custo total do evento foi estimado em $\mathrm{R} \$ 1,89$ bilhões entre

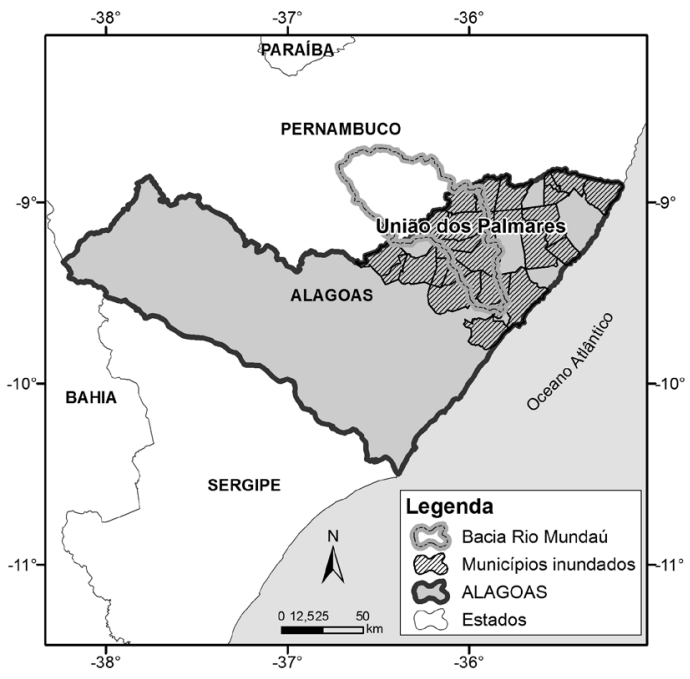

Figura 2. Mapa de Alagoas, bacia do rio Mundaú e municípios com inundações em 2010. perdas e danos, dos quais $\mathrm{R} \$ 1,58$ bilhões representam os custos estimados com os danos nos setores de habitação, transporte e educação. A maior parte do setor habitacional foi sobre a população de baixa renda ${ }^{24}$. Para as famílias, a destruição das moradias é um dado devastador que a afeta a saúde emocional e as condições socioeconômicas ${ }^{22}$.

Foi destruído um total de 43 unidades de saúde, comprometendo a oferta de atenção à saúde da população nos municípios. Em média, cada unidade de saúde destruída ou danificada tinha valor aproximado de $R \$ 750$ mil, sendo $R \$ 450$ mil de infraestrutura e R $\$ 300$ mil em equipamentos. Entre as unidades destruídas, somente uma, no município de Paulo Jacinto, era um hospital. Houve perdas de várias ambulâncias na inundação. Além disso, nos municípios onde foi declarada situação de emergência ou estado de calamidade pública, quase $16 \%$ das unidades de saúde foram danificadas. Isto significa que a capacidade do setor não estava disponível durante as fases prioritárias de resposta e recuperação ${ }^{24}$.

Em termos de impactos humanos imediatos foram registrados 36 óbitos, 1.393 enfermos e 1.131 feridos. Entre os 36 óbitos destacam-se os causados por afogamento e submersão acidental. O município de Branquinha, um dos mais atingi-

Tabela 1.Desalojados, desabrigados, feridos, enfermos e mortos, por município em consequência da inundação ocorrida em Alagoas em 2010.

\begin{tabular}{lcrrrrr}
\hline \multicolumn{1}{c}{ Município } & Desalojados & Desabrigados & Feridos & Enfermos & Mortos & Afetados \\
\hline Atalaia & 2.992 & - & - & - & - & 10.500 \\
Branquinha & 3.114 & 494 & 421 & 139 & 6 & 7.470 \\
Cajueiro & 3.510 & 411 & 52 & 34 & - & 16.900 \\
Capela & 180 & 279 & 2 & 14 & - & 8.900 \\
Itabeguara & 234 & - & - & - & - & 15.836 \\
Jacuípe & 725 & 153 & - & - & - & 7.045 \\
Joaquim Gomes & 358 & 81 & - & 151 & 1 & 14.950 \\
Jundia & 258 & 30 & - & - & - & 750 \\
Matriz de Camaragibe & 2.500 & 1.198 & - & - & - & 3.698 \\
Murici & 7.000 & 1.864 & 154 & 802 & 9 & 28.894 \\
Paulo Jacinto & 585 & 488 & 21 & 12 & 1 & 5.982 \\
Quebrangulo & 2.504 & 2.296 & 16 & - & - & 12.159 \\
Rio Largo & 4.000 & 6.000 & 123 & 69 & 9 & 16.200 \\
Santana do Mundaú & 2.582 & 3.758 & 70 & 40 & 2 & 12.039 \\
São José da Lage & 3.930 & 703 & - & - & - & 27.864 \\
São Luiz do Quintude & 1.755 & 305 & - & - & - & 3.240 \\
São Miguel dos Campos & 3.000 & 420 & 5 & - & - & 4.880 \\
Satuba & 644 & 15 & - & - & - & 1.574 \\
União dos Palmares & 2.654 & 8.836 & 220 & 132 & 8 & 62.279 \\
Viçosa & 500 & 1.256 & 47 & - & - & 8.014 \\
Total & 44.052 & 28.577 & 1.131 & 1.393 & 36 & 269.651 \\
\hline Fon & & & & & \\
\hline
\end{tabular}

Fonte: Secretaria Nacional de Defesa Civil e Defesa Civil de Alagoas. 
dos, registrou seis óbitos por afogamento, quando no ano anterior e no subsequente registrara apenas um. Os efeitos de médio prazo incluem as doenças transmissíveis. De acordo com dados da Secretaria de Estado da Saúde de Alagoas, somente no período compreendido entre 18 de junho e 12 de julho de 2010, o Laboratório Central havia recebido 26 exames para sorologia de leptospirose, dos quais 13 foram positivos ${ }^{26}$. Os efeitos de longo prazo incluem os problemas psicológicos que podem persistir por muito tempo após a inundação e outros problemas decorrentes do fato de as populações viverem em locais superlotados, com estoque limitado de alimentos, contaminação cruzada das fontes de água, com material fecal e produtos tóxicos e químicos e falta de saneamento ${ }^{27}$.

Para reduzir os impactos do desastre sobre as populações expostas a eles, o governo federal anunciou a liberação de um bilhão de reais para obras emergenciais ${ }^{25}$, repetindo os processos que ocorrem a cada nova inundação em Alagoas, os quais envolvem ações pós-desastres como: militarização da ajuda aos desabrigados, liberação de fundos de emergência e promessas de reconstrução de casas, escolas e edifícios públicos. Após alguns meses ou anos, quando os impactos de curto e médio prazo vão se tornando esquecidos e invisíveis, parte da população passa a viver a cronificação do desastre através da espera de construção de novas casas para reconstrução de suas vidas.

\section{Cárcere sem crime: o caso dos "abandonados" na "Terra da Liberdade"}

O município de União dos Palmares, situado na Zona da Mata Norte de Alagoas, um dos afetados pelas inundações de 2010, tem um importante legado na História do Brasil. Foi na Serra da Barriga que Zumbi dos Palmares fundou e liderou um dos maiores quilombos do Brasil colonial no regime escravocrata. Estava em jogo a liberdade individual e coletiva, e foi por essa condição humana que eles lutaram até a morte durante boa parte do século XVII.

Se a desigualdade teve uma das mais fortes expressões na ausência de liberdade que caracteriza o regime escravocrata, esta ganha nova e sutil configuração ao longo do século XX e início de XXI. Passados mais de trezentos anos do fim do Quilombo dos Palmares, as desigualdades estruturais do latifúndio monocultor canavieiro ganham novos contornos, aprisionando cerca de cem famílias na condição de "abandonados" pela sociedade. Elas vivem no perímetro da sede municipal, habitando escombros da antiga Colônia Prisional Santa Fé.

Nessa Colônia Prisional, há vinte pavilhões que nunca funcionaram como presídio federal. Desde o final da década de 1970, o local vem sendo habitado ora por desabrigados de inundações passadas, ora por excluídos da sociedade canavieira. Existem cerca de mil pessoas vivendo em precárias condições de vida, onde não há emprego formal, coleta de lixo, água tratada ou esgotamento sanitário. Mesmo elementos mínimos para condições de vida decente são ausentes, como sanitários, defecando-se ao ar livre, próximo aos pavilhões. A água é captada pelas mulheres (desde adolescentes até crianças e idosas) em um cano rompido a cerca de $500 \mathrm{~m}$ do local. Quando falta água nesse cano, a solução é usar a água suja de um riacho que passa dentro de uma propriedade privada vizinha ao terreno da colônia.

A eletricidade é feita por instalações precárias e sujeitas a curtos-circuitos em épocas de chuva, devido às muitas infiltrações nos tetos dos edifícios em ruínas.

A transmissibilidade intergeracional do risco está evidente no caso de famílias que por três gerações sucessivas são despejadas em Santa Fé. A trajetória de uma família exemplifica bem esse processo, pois a avó foi para a ex-colônia na inundação de 1972, a mãe na de 1989 e agora a filha seguiu para viver na cela da família após a inundação de 2000. Agora todos vivem lá, esperando uma oportunidade de "ganhar" uma casa do governo, como relatou um membro da família entrevistado durante a pesquisa de campo realizada em novembro de 2013 pelos autores. Tratase de uma rotina de abandono que identifica e exprime o reverso da cidadania ${ }^{18}$.

A situação desumana se reflete ainda numa perversa constatação: segundo relatos desses moradores, os inundados de 2010 que foram abrigados nos pavilhões já receberam desde 2012 suas casas construídas pelo Governo Federal num conjunto habitacional de cerca de 5.000 unidades. No total, existem quatro conjuntos habitacionais na cidade, totalizando cerca de 20.000 unidades, todas ocupadas pelos inundados de 2000 e 2010. Pela grande exposição na imprensa nacional, tais inundados foram "privilegiados" na construção de quatro novos bairros longe das margens do rio Mundaú, com casas, saneamento, pavimentação e quadras poliesportivas.

Os que restaram em Santa Fé são oriundos de inundações anteriores a 2000 e provenientes de 
outras cidades de Alagoas. São também os excluídos do sistema econômico hegemônico local (a plantation). Como o local está situado numa suave ondulação nas cercanias do perímetro urbano, podem-se ver os novos conjuntos habitacionais construídos para os desabrigados de 2010. Os "abandonados" de Santa Fé ensejam um futuro melhor: "uma casa num conjunto", como afirmaram várias moradoras na visita de campo.

A vulnerabilidade resulta, entre outras coisas, de condições de vida precárias. Mesmo entre os vulneráveis há alguns grupos que se tornam ainda mais vulneráveis, vivenciando sem possibilidades de mudança uma situação de cronificação do desastre, de perpetuação do ciclo vicioso da pobreza e das precárias condições de vida. Assim, chega-se à triste conclusão que hoje é mais vantajoso estar numa área de risco às inundações, pois, caso consiga sobreviver a um provável novo desastre, com uma inundação, pelo menos o "novo" inundado terá direito uma casa construída pelo Governo Federal. Aos “antigos” inundados não lhes foi concedido esse direito.

Os “abandonados” de Santa Fé estão presos por um crime que não cometeram: são pobres, desabrigados e esquecidos pela sociedade. São os fantasmas de antigas e "distantes" inundações, encarcerados e estrategicamente mantidos à longa vista dos habitantes formais, usineiros, políticos locais e nacionais. Eles não conseguem sair dessa prisão e alguns estão nela há mais de trinta anos. De fato, passados mais de três séculos, a luta pela liberdade continua na terra de Zumbi dos Palmares.

\section{Considerações finais}

O estudo de caso serviu para problematizar os conceitos de risco a desastres e sua associação com a vulnerabilidade social, bem como a pertinência com o quadro histórico e social de Alagoas. Isso se deu, entre outros condicionantes, devido ao corte de vegetação nativa ao longo das margens de rios para o aumento da área agrícola e o uso intensivo de fertilizantes químicos, especialmente a partir da década de 1970. Esse aumento da área agrícola, progressivamente, as- soreou os principais rios da região, estendendo as áreas inundáveis nos cursos dos rios para além dos limites naturais de seus leitos maiores.

Em 2010, essa expansão terminou por atingir justamente as populações lindeiras, para as quais nunca existiu qualquer atenção da parte do Poder Público. Assim, verificou-se que as populações marginalizadas passaram a ter uma maior exposição à periculosidade, como foi o caso dos moradores de Santa Fé.

Por fim, a conexão do conceito de vulnerabilidade com a saúde coletiva demonstra que, em condições de vulnerabilidade, não somente são maiores os riscos de sofrer doenças, lesões e óbitos com os desastres, mas que seus efeitos vão para além dos imediatos (óbitos e doenças), prolongando-se no tempo e cronificando precárias condições de vida e saúde. No futuro, as inundações apresentarão uma maior frequência, intensidade e gravidade. Portanto, a atuação da saúde deverá acontecer nas estratégias de prevenção, atenção e monitoramento para as áreas geográficas de maior exposição à periculosidade natural, associada à ocupação por populações com maior vulnerabilidade social. É possível prevenir e mitigar os desastres adotando medidas que permitam evitar impactos negativos sobre a população, os bens, os serviços e o meio ambiente.

\section{Colaboradores}

NCF Freire, CV Bonfim e CE Natenzon participaram igualmente de todas as etapas de elaboração do artigo. 


\section{Referências}

1. Jakubicka T, Vos F, Phalkey R, Marx M, Guha-Sapir D. Health impacts of floods in Europe - Data gaps and information needs from a spatial perspective. Lovaina: MICRODIS Report, Centre for Research on The Epidemiology of Disasters (Cred), School of Public Health, Catholic University of Louvain; 2010.

2. Zhang Q, Zhang J, Jiang L, Liu X, Tong Z. Flood Disaster Risk Assessment of Rural Housings - a case study of Kouqian Town in China. Int J Environ Res Public Health 2014; 11(4):3787-3802.

3. Goerl RF, Kobiyama M. Considerações sobre as inundações no Brasil. In: XVI Simpósio Brasileiro de Recursos Hídricos; 2005.

4. Castro ALC, Calheiros LB. Manual de Medicina de Desastre. V. 1. Brasília: Ministério da Integração Nacional Secretaria Nacional de Defesa Civil; 2007. Volume I.

5. Kouadio IK, Aljunid S, Kamigaki T, Hammad K, Oshi$\operatorname{tani} \mathrm{H}$. Infectious diseases following natural disasters: prevention and control measures. Expert Rev Anti Infect Ther 2012; 10(1):95-104.

6. Du W, FitzGerald GJ, Clark M, Hou XY. Health impacts of floods. Prehosp Disaster Med 2010; 25(3):265-272.

7. United Nations Conference on Sustainable Development (UNCSD). Disaster-resilient Societies - Facts and figures. [documento da internet]. 2012 [acessado 2014 jan 12], [cerca de 2 p.]. Disponível em: http://www. un.org/en/sustainablefuture/disasters.shtml

8. Doocy S, Daniels A, Murray S, Kirsch TD. The Human Impact of Floods: a Historical Review of Events 19802009 and Systematic Literature Review. PLoS Curr [periódico na internet] 2013 [acessado $2013 \mathrm{dez} 5$ 5] Disponível em: http://currents.plos.org/disasters/article/thehuman-impact-of-floods-a-historical-review-of-events -1980-2009-and-systematic-literature-review/

9. Ximenes EF. Enchentes e saúde: levantamento das diferentes abordagens e percepções, Região do Médio Paraí$b a, R J$ [dissertação]. Rio de Janeiro: Escola Nacional de Saúde Pública Sergio Arouca; 2010.

10. Cidade LCF. Urbanização, ambiente, risco e vulnerabilidade: em busca de uma construção interdisciplinar Cad Metrop 2013; 15(29):171-191.

11. Universidade Federal de Santa Catarina. Centro Universitário de Estudos e Pesquisas sobre Desastres. Atlas brasileiro de desastres naturais 1991 a 2010: volume Brasil. Florianópolis: CEPED UFSC; 2012.

12. Fragoso Junior CR, Pedrosa VA, Souza VCB. Reflexões sobre a cheia de junho de 2010 nas bacias do rio Mundaú e Paraíba. X Simpósio Regional Brasileiro de Recursos Hídricos. Fortaleza/CE. 2010. [documento da internet]. 2010 [acessado 2014 jan 12], [cerca de 20 p.] Disponível em: http://www.ctec.ufal.br/professor/vap/ Cheia2010.pdf

13. Freitas CM, Ximenes EF. Enchentes e saúde pública: uma questão na literatura científica recente das causas, consequências e respostas para prevenção e mitigação. Cien Saude Colet 2012; 17(6):1601-1616.

14. International Strategy for Disaster Reduction (ISDR). Global Assessment Report on Disaster Risk Reduction - Risk and poverty in a changing climate Invest today for a safer tomorrow. [documento da internet]. 2009 [acessado $2013 \mathrm{dez}$ 12], [cerca de 14 p.]. Disponível em: http://www.preventionweb.net/english/hyogo/gar/ report/documents/GAR_Prelims_2009_eng.pdf
15. Beck U. Vivir en la sociedad del riesgo mundial. Documentos CIDOB, Serie Dinámicas Interculturales, 8. Barcelona, CIDOB. Versión digital, 2007. [documento da internet]. 2007 [acessado 2014 jan 12], [cerca de 57p.]. Disponível em: http://www.cidob.org/es/publicaciones/ documentos_cidob/dinamicas_interculturales/vivir en_la_sociedad_del_riesgo_mundial_living_in_the world_risk_society

16. Alcantara-Ayala I. Geomorphology, natural hazards, vulnerability and prevention of natural disaster in developing countries. Geomorphology 2002; 47(2-4):107-124.

17. Blaikie P, Cannon T, David I, Wisner B. Vulnerabilidad: El entorno social, politico y económico de los desastres. Lima: A Rede; 1996.

18. Aragón G. Construcción y reconstrucción del desastre. México: Plaza y Valdés; 2011.

19. Barenechea J, Gentile E, Gonzalez S, Natenzon C. Una propuesta metodológica para el estúdio de la vulnerabilidad social em el marco de la teoría social del riesgo. PIRNA - Programa de Investigaciones en Recursos Naturales y Ambiente, Instituto de Geografía, FFyL/UBA. Versión digital, 2000. [documento da internet]. 2000 [acessado 2014 jun 18], [cerca de 13p.]. Disponível em: http://www.researchgate.net/publication/228456530_ Una_propuesta_metodolgica_para_el_estudio_de_la_ vulnerabilidad_social_en_el_marco_de_la_teora_social_del_riesgo

20. Valencio N, Siena M, Marchezini V. Abandonados nos desastres: uma análise sociológica de dimensões objetivas e simbólicas de afetação de grupos sociais desabrigados e desalojados. Brasília: Conselho Federal de Psicologia; 2011.

21. Confalonieri UEC, Marinho DP, Rodriguez RE. Public health vulnerability to climate change in Brazil. Clim Res 2009; 40:175-186.

22. Valencio N. Desastres, Ordem Social e Planejamento em Defesa Civil: o contexto brasileiro. Saúde Soc 2010; 19(4):748-762.

23. Confalonieri UEC. Mudança climática global e saúde humana no Brasil. Parcerias Estratégicas 2008; 27:324349 .

24. Banco Mundial (BM). Avaliação de Perdas e Danos: Inundaçoes Bruscas em Alagoas - Junho de 2010. Brasília: BM; 2012.

25. Souza JCO. Análise do evento climático extremo ocorrido na região leste de Alagoas: bacias hidrográficas dos rios Mundaú e Paraíba do Meio. RBGF 2011; 4(2):377395.

26. Alagoas. Secretaria de Estado da Saúde. Superintendência de Vigilância em Saúde. Informe Situação de Saúde - Enchentes e inundações. [documento da internet]. 2010 [acessado 2013 dez 12], [cerca de 19 p.] Disponível em: http://www.saude.al.gov.br/sites/default/files /informe_situacao_de saude diass i.pdf.

27. Alderman K, Turner LR, Tong S. Floods and human health: a systematic review. Environ Int 2012; 47:37-47.

Artigo apresentado em 06/03/2014

Aprovado em 06/06/2014

Versão final apresentada em 08/06/2014 